\title{
O que acontece depois da formatura?
}

\author{
What happens after graduation?
}

\section{¿Qué sucede después de la graduación?}

\author{
Márcia Roseli da Costa \\ Universidade do Vale do Itajaí (Univali), Itajaí/SC - Brasil \\ Cássia Ferri \\ Universidade do Vale do Itajaí (Univali), Itajaí/SC - Brasil
}

\begin{abstract}
Resumo
Objetivamos neste trabalho identificar a contribuição da formação profissional na educação superior para a empregabilidade. Analisamos os textos das Diretrizes Curriculares Nacionais (DCNs) e realizamos pesquisa com egressos de cursos de graduação de IES do sul do Brasil, identificando: perfil da atuação profissional e sugestões para a melhoria do curso. Confirmamos que há muitas incongruências entre o prescrito nos textos oficiais e os perfis de empregabilidade. Constatamos que o perfil prescrito pelas DCNs não se concretiza na totalidade, na medida em que se identificam baixas condições de empregabilidade e capacidade de análise crítica restrita. Concluímos que a formação de qualidade envolve as IES na adoção dos princípios de uma formação integral, com postura crítica e reflexiva diante do conhecimento e da vida profissional.
\end{abstract}

Palavras-chave: Educação superior, Egressos, Formação profissional

\begin{abstract}
This work aimed to identify the contribution of professional training in higher education for employability. We have analyzed the texts of the National Curricular Guidelines and performed research with higher education graduates in the South of Brazil, identifying the profile of professional practice and the suggestions to improve the course. We have confirmed that there are much incongruence between what is prescribed in the official texts and the profiles of employability. We have also observed that the profile prescribed by the National Curricular Guidelines is not fully materialized, as low conditions of employability and limited capacity for critical analysis were identified. We have concluded that quality training involves the HEls in adopting the principles of a holistic training, with critical and reflective attitude before knowledge and professional life.
\end{abstract}

Keywords: Higher education, Graduates, Professional training

\section{Resumen}

El objetivo de este trabajo es identificar la contribución de la formación profesional en la educación superior para la empleabilidad. Analizamos los textos de las DCNs y realizamos estudios con egresados de cursos de graduación de IES del Sur de Brasil, identificando el perfil de la actuación profesional y sugerencias para la mejoría del curso. Confirmamos que hay muchas incongruencias entre lo prescripto en los textos oficiales y los perfiles de empleabilidad. Comprobamos que el perfil prescripto 
por las DCNs no se concretiza en su totalidad, en la medida en que se identifican bajas condiciones de empleabilidad y restringida capacidad de análisis crítico. Concluimos que la formación de calidad involucra a las IES en la adopción de los principios de una formación integral, con postura crítica y reflexiva frente al conocimiento y a la vida profesional.

Palabras clave: Educación Superior, Egresados, Formación profesional

\section{Introdução}

A mudança nos modos de produção, o avanço da tecnologia e as rápidas transformações na sociedade geram um clima de incerteza em relação ao trabalho. Nesse contexto, as instituições universitárias recebem a função de buscar, no dizer de Saviani (1994), o estreitamento da relação entre os termos educação e trabalho, pelo reconhecimento de que a educação, ao qualificar os trabalhadores, pode contribuir para o desenvolvimento econômico e social do país. Essa função é reforçada pelo texto da Lei de Diretrizes e Bases da Educação Nacional - LDB no 9.394/1996, que aponta como a segunda finalidade da educação superior "formar diplomados nas diferentes áreas de conhecimento, aptos para a inserção em setores profissionais e para a participação no desenvolvimento da sociedade brasileira, e colaborar na sua formação contínua" (BRASIL, 1996).

Dentre as políticas públicas adotadas para a implementação da LDB 9.394/96, destaca-se, como política de currículo, a definição de Diretrizes Curriculares Nacionais (DCNs) -, para os cursos de graduação. Nas DCNs, são delineados os perfis profissionais, incorporados aos Projetos Pedagógicos dos cursos, sendo esperado que esses perfis correspondam às demandas das áreas de atuação profissional dos egressos.

Os egressos dos cursos de graduação foram incorporados ao debate, como sujeitos da pesquisa que realizamos numa universidade comunitária do sul do Brasil, para identificar se, e em que medida, a formação profissional nos cursos de graduação, baseada nos perfis prescritos pelas DCNs, contribui para a empregabilidade. Surgiu daí a pergunta título deste trabalho: O que acontece depois da formatura?

Assim, embora se reconheça a importância da formação profissional de nível superior, a tendência de caracterizar a educação superior de qualidade como a que 
oferece a melhor formação profissional causa inquietação suficiente para impulsionar a elaboração deste trabalho ${ }^{1}$.

\section{Por que os egressos?}

A escolha pelos egressos como público participante desta pesquisa, num primeiro momento, foi impulsionada pelos estudos do Sistema Nacional de Avaliação da Educação Superior - Sinaes, que revelaram uma tendência de destaque para questões sobre os egressos, na modificação dos seus instrumentos de avaliação (BRASIL, 2015). Os instrumentos de avaliação de curso e da Instituição de Ensino Superior - IES, nos processos de reconhecimento e credenciamento, respectivamente, passaram a tratar com mais ênfase esse público, seja para verificar o acompanhamento que as IES realizam com seus egressos, seja pela identificação do ambiente socioeconômico no qual eles se inserem.

No entanto, quando se fala em avaliação de cursos (BRASIL, 2012; BRASIL, 2015), a preocupação é apenas documental, remetendo ao perfil profissional dos projetos pedagógicos dos cursos e, por consequência, às competências e habilidades prescritas pelas DCNs. O direcionamento dado aos processos avaliativos institucionais, por meio da Avaliação das Instituições de Educação Superior - Avalies, não é o mesmo utilizado para o processo avaliativo dos cursos que compõem a IES (Avaliação dos Cursos de Graduação - ACG), pois são tratados pelos instrumentos de avaliação como partes isoladas de um todo que não se integra e não conversa entre si. Lacerda (2015), ao tratar do caráter formativo do Sinaes, que nos parece ser o foco da inclusão dos egressos na avaliação, nos indica que

O aspecto formativo do sistema somente se encontra na AVALIES, no processo de autoavaliação da IES, que, esse sim, tem condições de realizar um exame abrangente em tempo e espaço, com sujeitos envolvidos com a realidade institucional. (LACERDA, 2015, p.31)

Confirma-se aqui que o acompanhamento da concretização dos perfis prescritos pelas DCNs, de fato, não é favorecido pelo Sinaes, no que diz respeito à avaliação dos cursos. Faz falta, na ACG, a inclusão de indicadores que estimulem os cursos a ouvirem a fala dos egressos acerca da sua formação, das possibilidades e

\footnotetext{
1 Pesquisa realizada para a elaboração de tese apresentada ao colegiado do Programa de PósGraduação em Educação da Universidade do Vale do Itajaí, como requisito parcial para a obtenção do grau de doutora em educação.
}

Revista Educação Online, Rio de Janeiro, n. 26, set-dez 2017, p. 137-153 
dificuldades que enfrentam na vida profissional e que se relacionam à formação universitária recebida.

Ainda que o Sinaes já indique às IES, especialmente na Avalies, a pertinência de pesquisa focada nos egressos, a opção que fizemos se deu também pela importância de envolver na discussão, acerca da formação profissional, aqueles que fazem uso dela. Entendemos que todo movimento de reflexão, de avaliação, de mudança, de melhoria na educação superior deve levar em conta o que têm a dizer os sujeitos diretamente envolvidos. Lousada e Martins (2005), nesse sentido, afirmam que

Se uma das finalidades da Universidade é inserir na sociedade diplomados aptos para o exercício profissional, deve ter ela retorno quanto à qualidade desses profissionais que vem formando, principalmente no que diz respeito à qualificação para o trabalho. (p.74)

Assim, o egresso é percebido neste trabalho como um sujeito que, por já haver concluído a formação acadêmica, tem condições de avaliar o percurso da formação. No dizer de Meira e Kurcgant (2009)

O egresso enfrenta no seu cotidiano de trabalho situações complexas que o levam a confrontar as competências desenvolvidas durante o curso, com as requeridas no exercício profissional. Pode, a partir daí, avaliar a adequação da estrutura pedagógica do curso que foi evidenciado, bem como os aspectos intervenientes no processo de formação acadêmico. (p. 482)

Identificamos também as pesquisas que têm o egresso da educação superior como público e verificamos que são poucas as publicações que tratam dele e as pesquisas que o utilizam como participante.

Por se tratar de uma das principais, senão a principal entidade representativa da pesquisa em educação no país, fizemos a leitura e análise das publicações das reuniões anuais da Associação Nacional de Pesquisa em Educação - Anped. Para essa atividade, foram selecionados trabalhos da 30aㅡ $36^{\underline{a}}$ Reunião Anual, realizadas de 2007 a 2013, utilizando o critério de atualidade e, ainda, dessas reuniões, foram selecionados os Grupos de Trabalho - GT 09 - Trabalho e Educação, GT 11 Políticas de Educação Superior e GT 12 - Currículo. A escolha desses GTs se deu pela possibilidade de aproximação às discussões acerca da formação profissional universitária e da avaliação do ensino superior. No entanto, constatamos que não há trabalhos apresentados nas Anpeds que pesquisem a atuação profissional, a 
formação profissional, a visão de currículo ou da avaliação da educação superior na perspectiva dos egressos.

A despeito da escassez de publicações científicas que os incluam, podemos destacar duas importantes publicações do Inep, que tratam de resultados de projeto de cooperação técnica internacional entre o Ministério da Educação/Inep e o Programa das Nações Unidas para o Desenvolvimento (PNUD). Eles investigaram o desempenho do Sinaes, por meio de estudos e pesquisas, na forma de análise sobre a relação do egresso dos cursos de graduação avaliados no Enade 2005 e 2008 (2 ciclo avaliativo) e sua inserção no mercado de trabalho (BRASIL, 2015); e de "estudo analítico do desempenho do estudante participante do $3^{\circ}$ ciclo avaliativo e seu perfil de empregabilidade nas unidades federativas do Brasil" (BRASIL, 2012015, no prelo). A leitura dessas publicações serviu como base de reflexão para a realização do presente trabalho.

Acreditamos, assim, que o conjunto composto pela presença pouco significativa dos egressos no sistema de avaliação, pela sua ausência nos debates nas IES sobre a formação profissional e, ainda mais, pela ausência da fala dos egressos na pesquisa sobre a educação superior no país, é justificativa bastante para a inclusão das suas falas neste trabalho.

\section{Desenvolvimento}

Participaram da pesquisa os egressos da IES, no período compreendido entre 2004 e 2013, propositadamente, coincidente com a implantação do Sinaes. Nesse período, foram identificados, na IES, 28.697 egressos, obtendo como resultado a participação de 1.798 como respondentes da pesquisa.

Foi escolhida a pesquisa do tipo Survey, como metodologia, com aplicação de questionário previamente estruturado, composto por questões objetivas e uma questão dissertativa. Esse tipo de pesquisa se aplica ao presente trabalho, por se caracterizar pela coleta de dados e informações de um determinado grupo que representará a população-alvo (BABBIE, 1999).

O questionário aplicado aos egressos da IES teve 15 questões, que identificaram:

1. Situação de empregabilidade dos egressos - da formatura ao emprego atual; 
2. Local de trabalho dos egressos - área de atuação e a natureza da atual organização;

3. Cargo exercido e renda média alcançada;

4. Importância do desempenho no Enade para a profissão;

5. Contribuição do curso para atuação e desenvolvimento profissional;

6. Investimento próprio na formação;

7. Construção da carreira profissional pelos próprios egressos;

8. Sugestões de melhoria para o curso.

Para a elaboração das questões que tratam da contribuição do curso para o desenvolvimento profissional, foram estudados os perfis profissionais expressos nas diretrizes dos diversos cursos participantes da pesquisa, a partir das competências e habilidades presentes nesses documentos. O estudo resultou na elaboração de uma questão, em que os egressos identificam o nível de contribuição do seu curso para o desenvolvimento profissional, utilizando os atributos comuns: capacidade de comunicação; habilidade de trabalhar em equipe; capacidade de análise crítica; senso ético; criatividade na solução de problemas; capacidade de tomar decisão; capacidade empreendedora.

No escopo deste trabalho, entendemos competências como saberes que se convertem em ações, não somente restritas ao saber-fazer, mas a processos de tomada de decisão, de reação a demandas e ao uso criativo do que foi aprendido. No entanto, considerando as diferenças de formação, de atuação profissional e da realidade própria de cada área, pactuamos da reflexão de Sacristán (2013), sobre a aplicação indistinta da educação por competências:

Uma concepção rígida e burocrática desconhecedora dos limites das competências tem guiado a aplicação do modelo de educar por competências de forma uniforme a estudos muito diversos, desde as engenharias até a literatura; uma aplicação que poderíamos dizer ser contra a natureza em muitos casos. (p. 278)

No Quadro 1 vemos a frequência com que esses atributos aparecem nas diretrizes, considerando as diversas áreas de conhecimento: 
Quadro 1 - Síntese das Competências e habilidades nas DCNs

\begin{tabular}{|c|c|c|c|c|c|c|}
\hline $\begin{array}{l}\text { Competências e } \\
\text { Habilidades }\end{array}$ & $\begin{array}{l}\text { Ciências } \\
\text { da Saúde }\end{array}$ & $\begin{array}{l}\text { Ciências } \\
\text { Sociais e } \\
\text { Jurídicas }\end{array}$ & $\begin{array}{l}\text { Ciências } \\
\text { Sociais } \\
\text { Aplicadas }\end{array}$ & Licenciaturas & $\begin{array}{c}\text { Cursos } \\
\text { Superiores } \\
\text { de } \\
\text { Tecnologia }\end{array}$ & Total \\
\hline Ética & 35 & 0 & 20 & 5 & 1 & 61 \\
\hline Comunicação & 11 & 0 & 8 & 2 & 0 & 21 \\
\hline Empreendedorismo & 7 & 0 & 4 & 1 & 1 & 13 \\
\hline Trabalho em equipe & 21 & 0 & 8 & 4 & 0 & 33 \\
\hline $\begin{array}{l}\text { Resolução de } \\
\text { problemas }\end{array}$ & 18 & 0 & 8 & 7 & 0 & 33 \\
\hline Análise crítica & 5 & 1 & 13 & 6 & 0 & 25 \\
\hline Tomada de decisão & 5 & 1 & 8 & 6 & 0 & 20 \\
\hline $\begin{array}{l}\text { Conhecimento } \\
\text { teórico e prático }\end{array}$ & 107 & 12 & 73 & 46 & 5 & 243 \\
\hline
\end{tabular}

Fonte: Elaborado pela autora (2017).

Embora o conhecimento seja imprescindível a qualquer processo formativo, o destaque ao conhecimento teórico e prático nas DCNs é revelador de uma formação ainda pautada no ensino tradicional, que continua destacando a formação eficaz como aquela que propicia a aplicação de conhecimentos recebidos. Canário (2003) indica que essa forma de pensar a formação pode ser traduzida pela

Sobrevalorização da anterioridade da formação, relativamente à acção e à mudança; pela sequencialidade do conhecimento científico-conhecimento tecnológico-treino que corresponde a uma matriz fundamental da forma escolar; por uma orientação dominante para a capacitação individual. (p. 129)

A ausência da categoria empreendedorismo, na maioria dos cursos, é um destaque que causa estranhamento, por se tratar de tema comum ao discurso da própria universidade e das agências que discutem as questões mais atuais do mundo do trabalho. Shiroma e Coan (2012), tecendo críticas ao empreendedorismo como imposto pela lógica das políticas públicas de currículo, concluem que

a base epistemológica que sustenta a educação para o empreendedorismo é a mesma que nutre as relações sociais de produção capitalistas e fomenta a corrida pelos sonhos individuais que tentam forjar um jovem de novo tipo, limitados à pequena política, aprisionados aos projetos individuais que se pode conquistar em curto prazo. (p. 273)

Também não pode passar despercebido o pequeno número de menções a competências e habilidades categorizadas, com predomínio da análise crítica e da ética, considerando os problemas sociais e éticos com os quais deve se deparar o egresso dos cursos de graduação no exercício das diversas profissões. Para Goergen (2010), 
A educação superior deve contribuir, no contexto da pesquisa, do ensino, da extensão e do trabalho cultural, para uma refundação ética e moral da sociedade mediante a substituição da ética individual e solipsista por uma ética de corresponsabilidade e da solidariedade. (p.34)

No levantamento dos perfis profissionais das diretrizes dos cursos investigados, é possível perceber a tendência à vocação para a responsabilização, o compromisso, a alta produtividade e liderança, ao lado de enunciados sobre os grandes temas transversais, como o respeito às diferenças, sejam elas sociais, raciais ou de gênero, a ética pessoal e profissional, o respeito ao meio ambiente, enfim, a um perfil de cidadania como definida por Garcia (2010) "em termos de habilidades necessárias a uma economia global e a uma sociedade do conhecimento, que se fundamenta na produção flexível, no uso da tecnologia" (p.451).

A análise das respostas dos egressos possibilitou fazermos um desenho de quem é esse egresso e demonstrar que o perfil prescrito nas Diretrizes Curriculares Nacionais não é exatamente o que se concretiza com a formatura e nem se materializa como o perfil adequado para as melhores condições de empregabilidade. Senão, vejamos:

Figura 1 - Formação X Perfil de empregabilidade dos egressos

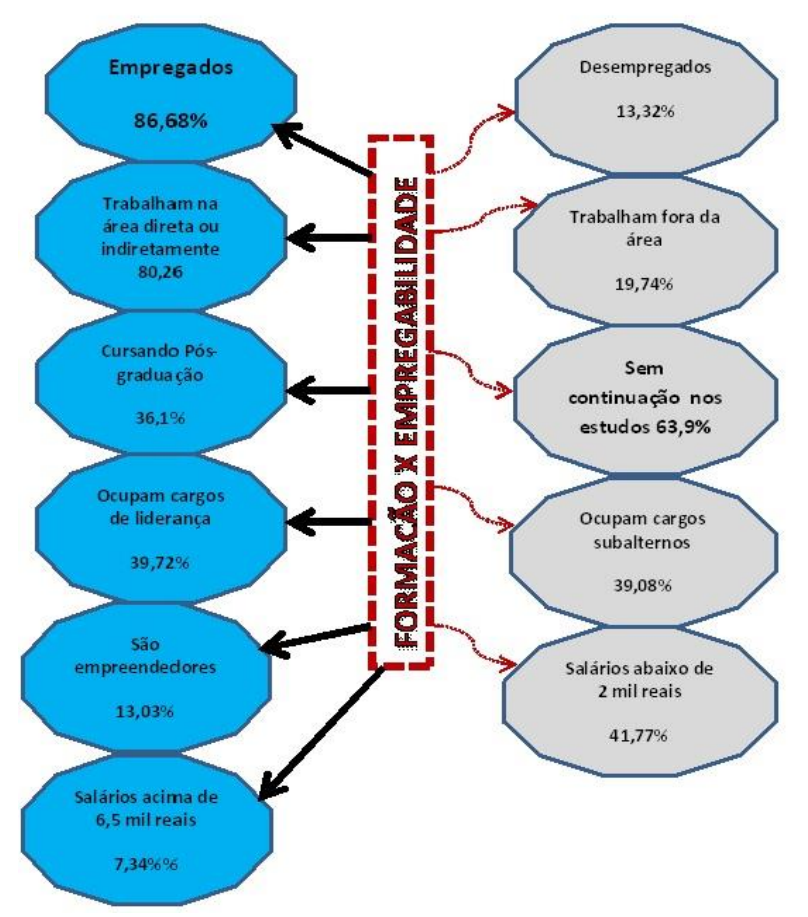

Fonte: Elaborado pela autora (2017) 
Na Figura 1, demonstramos que, embora alguns resultados apontados na pesquisa com os egressos tenham revelado aspectos animadores, como, por exemplo, o alto percentual de empregados no momento da pesquisa (86,68\%) e o percentual significativo dos que trabalham, direta ou indiretamente, na área de formação $(80,26 \%)$, há outros aspectos que se destacam negativamente. Dentre eles, os baixos salários dos egressos, uma vez que $41,77 \%$ deles declara receber salários inferiores a 2 mil reais e somente 7,34\% recebem salários superiores a 6,5 mil reais.

A análise dos perfis apresentados pelos egressos na realidade do mercado de trabalho nos permite dizer que a expectativa acerca do potencial da formação para a empregabilidade se revela irreal. No cenário atual, cai por terra a falsa pretensão de que a formação em curso superior garantirá "um lugar ao sol", e que os perfis prescritos pelas políticas públicas servirão para o melhor e mais adequado preparo do jovem para enfrentar e ser bem-sucedido no mercado profissional.

Crozier (1979) afirma que "sabemos hoje que a formação não cria empregos e que a realidade social não muda por decreto" (CROZIER apud CANÁRIO, 2003, p. 117), destacando uma das (in)congruências que marcam a formação profissional universitária: a prescrição, pelas Diretrizes Curriculares Nacionais, de perfis profissionais "desejáveis" para uma realidade social que muda num ritmo acelerado, para um mercado incerto e imprevisível, para sujeitos com identidades indefinidas.

A última questão do instrumento solicitou sugestões de melhoria, para que os cursos de graduação no país formem profissionais líderes, competentes e com perfil de empregabilidade.

Após a leitura exploratória das respostas, tomamos como base as dimensões instituídas pelo Sinaes para a ACG (BRASIL, 2004), a priori, para classificá-las como: organização didático-pedagógica; corpo docente; e instalações físicas.

A escolha pelas dimensões da ACG como classificação dos dados dessa questão se deu pela compreensão da possibilidade de organização das respostas a partir de uma lógica estrutural (BARDIN, 1977), que relaciona os achados partindo de um ponto comum às políticas de educação superior no país - o Sistema de Avaliação, permitindo melhor compreensão do conjunto.

As respostas foram agrupadas por similaridade, criando padrões de respostas pelos elementos comuns entre elas, com o objetivo de "fornecer, por condensação, 
uma representação simplificada dos dados brutos" (BARDIN, 1977, p.119), como se vê no Quadro 2:

Quadro 2 - Dimensões e padrões de resposta da questão: sugestões de melhoria para o seu curso de graduação

\begin{tabular}{|c|c|}
\hline DIMENSÕES & PADRÕES DE RESPOSTA \\
\hline \multirow{3}{*}{ Instalações físicas } & Laboratórios mais equipados conforme as tendências de mercado \\
\hline & Biblioteca com mais títulos e mais atualizada \\
\hline & Estrutura física mais adequada e maior incentivo ao seu uso pelos alunos \\
\hline \multirow{7}{*}{ Corpo docente } & Professores que exijam/incentivem mais os alunos \\
\hline & Melhor qualificação/atualização/capacitação do corpo docente \\
\hline & Melhor didática dos professores/ Professores com mais perfil docente \\
\hline & Professores que atuem na área específica \\
\hline & Professores mais éticos \\
\hline & Avaliação do trabalho docente mais criteriosa \\
\hline & Valorização dos professores \\
\hline \multirow{39}{*}{$\begin{array}{l}\text { Organização didático- } \\
\text { pedagógica }\end{array}$} & Cursos/aulas mais práticas, mais atualizados \\
\hline & Curso mais alinhado ao mercado de trabalho \\
\hline & Mais estágio/mais qualificados \\
\hline & Apoio ao empreendedorismo \\
\hline & Oferta de curso/disciplina específico(a) \\
\hline & Estimular senso crítico, ética e reflexão \\
\hline & Maior interação teoria e prática \\
\hline & Fazer mais parcerias com empresas para oportunidades aos alunos \\
\hline & Programas de trainee/formação de líderes \\
\hline & Mais pesquisa científica \\
\hline & Orientar para ingresso no mercado de trabalho \\
\hline & Trabalhar comportamentos/atitudes com os alunos \\
\hline & Mais viagens/visitas técnicas \\
\hline & Analisar melhor a matriz curricular \\
\hline & Avaliação criteriosa/aplicação prática dos conhecimentos \\
\hline & Cursos mais focados em fundamentos/objetivos \\
\hline & Conteúdos mais atualizados \\
\hline & Seminários com a participação de egressos \\
\hline & $\begin{array}{l}\text { Intercâmbio de universitários para oferecer mais oportunidades de } \\
\text { aprendizagem }\end{array}$ \\
\hline & Criar empresas-modelo/incubadoras \\
\hline & Atividades de extensão - extraclasse - com a comunidade \\
\hline & Rever disciplinas com conteúdos irrelevantes \\
\hline & Exigir que os alunos leiam mais \\
\hline & Melhorar a qualidade do curso \\
\hline & Incentivar e orientar trabalho em equipe \\
\hline & Contra educação a distância/disciplinas \\
\hline & Flexibilidade curricular \\
\hline & Domínio da língua portuguesa e matemática \\
\hline & Oferta de disciplinas opcionais \\
\hline & Ênfase em áreas específicas \\
\hline & Interação entre cursos/disciplinas \\
\hline & Currículo adaptado para cada região/situação \\
\hline & Melhor aproveitamento do tempo de aula \\
\hline & Incentivar a continuação de estudos \\
\hline & Orientação profissional antes do ingresso \\
\hline & Trabalhos em grupo com a comunidade \\
\hline & Maior disponibilidade de tempo/dedicação dos professores \\
\hline & Diminuir número de alunos por sala \\
\hline & Ensino por competências \\
\hline
\end{tabular}

Revista Educação Online, Rio de Janeiro, n. 26, set-dez 2017, p. 137-153 


\begin{tabular}{|l|l|}
\hline \multicolumn{1}{|c|}{ DIMENSÕES } & \multicolumn{1}{c|}{ PADRÕES DE RESPOSTA } \\
\hline \multirow{4}{*}{} & Aumentar média de 6 para 7 ou 8 na admissão \\
\cline { 2 - 2 } & Prova ao final do curso para exercer profissão \\
\cline { 2 - 2 } & Ouvir alunos nas decisões curriculares \\
\cline { 2 - 2 } & Diminuir mudanças na matriz curricular \\
\cline { 2 - 2 } & Oferta de cursos em diferentes turnos \\
\cline { 2 - 2 } & Transformar cursos de tecnologia em bacharelado \\
\hline
\end{tabular}

Fonte: Elaborado pela autora (2017)

Em relação às instalações físicas, as falas dos egressos são pouco significativas. No entanto, podemos perceber a pertinência das suas sugestões, que vão ao encontro de uma formação universitária de qualidade.

Ferri (2010) diz que, para um projeto de ensino e aprendizagem responsável e coerente, "é preciso refletir sobre o papel pedagógico do professor na construção da qualidade das aprendizagens no ensino superior e defini-lo no âmbito da instituição" (p. 159). Por isso, acreditamos que a aquisição de equipamentos, de livros ou a montagem de laboratórios devem fazer parte do projeto pedagógico da IES e dos cursos, num movimento participativo, com o envolvimento dos docentes que farão acontecer a formação.

As sugestões dos egressos sobre o corpo docente foram significativas, do ponto de vista numérico e de conteúdo. Entendemos o professor como gestor do conhecimento, o que torna destacado o trabalho docente na busca da qualidade do ensino superior, pois "O professor é o agente mais próximo do currículo" (MUÑOZ, 2013, p. 499); é ele quem decide o que e como ensinar; é ele quem avalia e acompanha o processo didático na sala de aula; é ele quem faz as escolhas que farão acontecer o processo de ensino e aprendizagem e, a depender da sua ação, será possível promover a melhoria e a mudança ou, simplesmente, reproduzir, como destacado por Muñoz (2013). Por isso, acreditamos em um processo de formação, em que o professor organize o seu trabalho didático-pedagógico amparado em um "equilíbrio entre a teoria e a prática, o saber e a experiência, a reflexão, a ação e o pensamento, tanto para seu desenvolvimento pessoal quanto profissional" (MUÑOZ, 2013, p.501).

A preocupação com o "como acontece a formação" se reflete nas falas dos egressos, e, aqui, optamos por traduzir como "Organização Didático-pedagógica". Nas sugestões dos egressos, vemos a preocupação com a qualidade dos cursos, e ficou claro que as ideias se centraram em questões pertinentes ao desenvolvimento curricular. 
Quando falamos em currículo, nos referimos a toda a organização do processo de ensino e aprendizagem na educação superior. Compreende-se, nesse sentido, não somente os elementos presentes nos documentos oficiais governamentais, institucionais ou mesmo de produção do professor, como o plano de ensino, mas também todos os movimentos que estão explícitos e implícitos no conjunto das ações que configuram o percurso dos cursos de graduação e que se refletem no cotidiano da sala de aula.

No quadro das sugestões dos egressos, se destaca a preocupação com o que deve ser trabalhado/ensinado/aprendido na formação universitária. É fato que, na definição sobre o que a educação superior deve ensinar, não se pode fechar os olhos diante da realidade das exigências do mundo que aí está, do qual fazemos parte, queiramos ou não. Ferri (2010) afirma que

A reorganização das forças produtivas no mundo do trabalho e o modo social vigente
tornam hegemônicas as ideias de que, no futuro, o que prevalecerá será a
necessidade de autoaprendizagem das pessoas. Assim, é preciso assegurar um
saber geral que subsidie o processamento de novos conhecimentos e a versatilidade
nos processos de adaptação às novas atividades no mundo do trabalho. (p. 167)

As sugestões dos egressos apontam para um modelo pedagógico que é a reprodução do modelo de educação proposto pelos documentos da reforma da educação superior, numa lógica de transposição do modo de funcionamento do mercado de trabalho para a prática. No dizer de Canário (2003), é incorporada a lógica, em que “Uma formação 'eficaz' é, então, 'transferida', por um processo de 'aplicação', o que transforma a formação num processo de reprodução de normas e gestos, estabelecidos e aprendidos a priori" (p.130).

Algumas poucas falas dos egressos sobre como ensinar e aprender pedem por "atividades de extensão - extraclasse - com a comunidade"; "trabalhos em grupo com a comunidade"; "interação entre cursos/disciplinas"; "incentivar e orientar trabalho em equipe". Essas falas revelam a adesão a um modelo formativo, cujo foco não é o conteúdo como um fim, mas percebido como um meio para uma formação mais ampla, para uma formação integral que os prepare para a atuação social, como reforçado por Goergen (2010): “Formação acadêmica de qualidade é muito mais que preparação profissional para o mercado, porque envolve a formação do ser humano integral enquanto cidadão político e ético” (p.25).

As solicitações dos egressos por "curso mais alinhado ao mercado de trabalho"; "fazer mais parcerias com empresas para oportunidades aos alunos"; 
"programas de trainee/formação de líderes"; "orientar para ingresso no mercado de trabalho"; "orientar profissionalmente antes do ingresso"; "intercâmbio de universitários para oferecer mais oportunidades de aprendizagem" apontam como tarefa própria da universidade a inclusão dos estudantes no mercado de trabalho.

Quer parecer que a universidade se torna responsável por resolver a crise do trabalho e os problemas relacionados ao desemprego de massas. No entanto, o que percebemos é que a crise do trabalho é marcada no imaginário das pessoas, forjada pelos discursos políticos, do mercado e do quase mercado, pela ideia que remete a responsabilidade da crise às agências formadoras, como também destaca Canário (2003):

A articulação estreita entre as políticas de educação e formação e as políticas de emprego serve a gestão política dos problemas sociais do desemprego e da precarização do trabalho e induz à ideia de que os problemas de inserção satisfatória no mercado de trabalho seriam uma consequência do défice de qualificações dos trabalhadores. (p.199)

Além disso, nas sugestões dos egressos, a avaliação seria impulsionadora da qualidade da formação, quando pedem por uma "Avaliação criteriosa/aplicação prática dos conhecimentos"; "Aumentar média de 6 para 7 ou 8 na admissão" ou mesmo por "Prova ao final do curso para exercer profissão". Jiménez Sánchez (2013) indica que "a avaliação deve ter um caráter formativo, motivador e orientador, para que sirva como mecanismo de reflexão e autorregulação, tanto para o aluno quanto para o professor" (p.378).

\section{Conclusões}

As políticas públicas para a educação superior, expressas em documentos oficiais, tais como as DCNs ou o próprio Sinaes, estão focadas na formação para o atendimento a um desenvolvimento econômico, conforme os preceitos do modelo econômico vigente. No entanto, percebemos que esses movimentos nem sempre conseguem ser eficazes. Canário (2013) diz que "A euforia e a decepção que têm acompanhado o crescimento exponencial das atividades formativas são um fenómeno comum a diferentes domínios da atividade social" (p. 123).

Os achados na pesquisa com os egressos demonstram incongruências significativas entre a formação prescrita e, portanto, a considerada como de qualidade pelas políticas públicas, e os resultados dessa formação no cotidiano do mundo do trabalho. A pesquisa revelou que a preocupação dos egressos é 
reforçada sobre o conhecimento prático, diretamente relacionado à profissão, incorporando a tendência instrumental como o caminho mais apropriado para a formação profissional. Essa tendência se revela como uma das incongruências entre o perfil prescrito e o perfil de empregabilidade dos egressos.

Junto à questão do conhecimento teórico e prático, a formação ao longo da vida passa a ser uma necessidade indispensável na dita sociedade do conhecimento. Sacristán (2013) nos lembra que vivemos num momento em que a informação e o conhecimento são de extrema relevância para o funcionamento da sociedade, e que os indivíduos engajados nessa perspectiva têm mais oportunidades. Isso evidencia outra incongruência, quando apenas $36,1 \%$ dos egressos cursam pós-graduação e apenas 48,45\% realizam investimentos na própria formação.

No que se refere à formação, os egressos expressaram suas sugestões de forma significativa, ao pedir por maior flexibilidade curricular. Os achados da pesquisa revelam que $19,74 \%$ dos egressos atuam profissionalmente fora de sua área de formação, e a metade deles, por não encontrar colocação na área. Enguita (2013) nos diz que "A organização do trabalho (como também a do capital, da tecnologia e da gestão) evolui no sentido da existência de flexibilidade como resposta a mercados incertos e dinâmicos, ciclos tecnológicos mais (...) etc."(p. 65).

Um dos princípios de formação da reforma se encontra, sem dúvida, na assunção de competências para as definições curriculares da educação superior. No entanto, a constatação de incongruências entre o perfil prescrito, na forma de competências e habilidades pelas diretrizes, e o perfil de empregabilidade dos egressos nos permitem, ainda, tecer algumas considerações.

Talvez a maior das incongruências esteja na constatação de que a formação prescrita pelas diretrizes e adotada pelas instituições de ensino superior nos seus Projetos Pedagógicos, de fato, não se concretiza como esperado.

E, então, volta a questão: O que acontece depois da formatura? Apesar de inúmeras histórias de sucesso profissional e pessoal que observamos entre os egressos, infelizmente, em sua maioria, constatamos um perfil indicativo de uma formação insuficiente para o sucesso desejado, com baixas condições de empregabilidade e capacidade de análise crítica restrita em relação às situações vivenciadas no mercado de trabalho. 
Para nós, a formação deve estar vinculada a uma concepção de aprendizagem e de educação pautada nos princípios de uma formação integral, que se preocupe com o desenvolvimento pessoal do aluno num sentido mais amplo do que recomendam as organizações. Zabalza (2004) destaca que o mercado de trabalho já se dá conta que a formação focada apenas no preparo técnico começa a não fazer sentido; "começa a predominar a ideia de que é preferível, inclusive do ponto de vista dos empregadores, que os indivíduos tenham uma formação geral suficientemente ampla e polivalente a ponto de permitir a mobilidade profissional" ( $p$. 49).

Precisamos de uma formação universitária, que se comprometa com as demandas da sociedade por melhor preparo do egresso, para que ele possa desempenhar as funções profissionais com competência. Além disso, ele deve ser preparado para atuar como cidadão consciente, solidário e participativo, exercer o direito de análise crítica do contexto social, econômico e político que o cerca, tendo como princípio uma postura reflexiva em todos os aspectos do conhecimento e das experiências profissionais e sociais que vivencia. Isso pode ser feito, não mediante a imposição de documentos oficiais, mas pela via do comprometimento das instituições de ensino e dos docentes com a construção de um currículo reflexivo, em que o aluno seja sujeito ativo, um currículo que favoreça o desenvolvimento do pensamento e cujo foco principal seja a qualidade das aprendizagens.

\section{Referências bibliográficas}

ANPED. Reuniões científicas nacionais: 30 a 36. Trabalhos dos GTs. 2007 à 2013. Disponível em <www.anped.org.br/reunioes-cientificas/nacional>. Acesso em 20 mar 2014.

BABBIE, E. Métodos de pesquisas de Survey. Belo Horizonte: UFMG, 1999. (Coleção Aprender).

BARDIN, L. Análise de conteúdo. Lisboa: Edições 70, 1977.

Egressos e empregabilidade: análise da relação do egresso dos cursos de graduação avaliados no ENADE 2005 e 2008 e sua inserção no mercado de trabalho. Brasília: INEP, 2015. 4 v.

Produto 04, denominado documento técnico, contendo estudo analítico do desempenho do estudante participante do $3^{\circ}$ ciclo avaliativo e seu perfil de empregabilidade nas unidades federativas do Brasil, considerando a absorção pelo mercado de trabalho e o respectivo nível salarial, a partir de amostragem e contribuições da formação recebida na graduação, com atenção às características 
das áreas do conhecimento, unidades federativas e regiões geográficas. Brasília: INEP, 2014-2015 (no prelo).

BARDIN, L. Instrumento de avaliação de cursos de graduação presencial e a distância. Brasília: INEP, 2012. Disponível em: <http://download.inep.gov.br/educacao_superior/avaliacao_cursos_graduacao/instru mentos/2012/instrumento_com_alteracoes_maio_12.pdf >. Acesso em 12 jul 2015.

. Instrumento de avaliação de cursos de graduação presencial e a distância.

Brasília: $\quad$ INEP, $2015 . \quad$ Disponível em <http://download.inep.gov.br/educacao_superior/avaliacao_cursos_graduacao/instru mentos/2015/instrumento_cursos_graduacao_publicacao_agosto_2015.pdf>. Acesso em 15 nov 2015.

. Orientações gerais para o roteiro da autoavaliação das instituições. Brasília: $\quad 2004 . \quad$ INEP, Disponível em <http://download.inep.gov.br/download/superior/sinaes/orientacoes_sinaes.pdf>.

Acesso em 10 jul 2014.

Sinaes - Sistema Nacional de Avaliação da Educação Superior: Da Concepção à regulamentação. 2ª ed. Brasília: INEP, 2004. Disponível em: <http://www.publicacoes.inep.gov.br/portal/download/700>. Acesso em 10 jul 2014.

. Lei n. 9.394, de 20 de dezembro de 1996. Estabelece as diretrizes e bases da educação nacional. Diário Oficial da União, Brasília, 23 dez. 1996.

Lei n. 10.861, de 14 de abril de 2004. Institui o Sistema Nacional de Avaliação da Educação Superior - SINAES e dá outras providências. In. Diário Oficial da União, Brasília, 15 de abril de 2004a. Disponível em: <http://www.planalto.gov.br/ccivil_03/_ato2004-2006/2004/lei/l10.861.htm>. Acesso em: 24 abr 2012.

CANÁRIO, Rui. Formação e mudança no campo da saúde. In. Formação e situações de trabalho. $2^{\underline{a}}$ ed. Porto: Porto Editora, 2003.p. $\overline{117-146 .}$

A "aprendizagem ao longo da vida" análise crítica de um conceito e uma política. CANÁRIO, R. (Org.). Formação e situações de trabalho. $2^{\underline{a}}$ ed. Porto: Porto Editora, 2003. p.189-207.

ENGUITA. M. F. As forças em ação: sociedade, economia e currículo. In. SACRISTÁN, J. G. (Org.). Saberes e incertezas sobre o currículo. Porto Alegre: Penso, 2013. p.54-70.

FERRI, C. Educação geral: um desafio pedagógico no ensino superior. In. PEREIRA, E. M. de A. (Org.). Universidade e currículo: perspectivas de educação geral. Campinas: Mercado de Letras, 2010. p.157-168.

GARCIA. M. M. A. G. Políticas educacionais contemporâneas: tecnologias, imaginários e regimes éticos. Revista Brasileira de Educação, v. 15 n. 45, p.445-455, set-dez 2010.

GOERGEN, P. L. Formação superior: entre o mercado e a cidadania. In. PEREIRA, E. M. de A. (Org.). Universidade e currículo: perspectivas de educação geral. Campinas: Mercado de Letras, 2010. p.17-40.

LACERDA, L. L. V. de. Sistema Nacional de Avaliação do Ensino Superior: sistema de avaliação ou exame de desempenho?. 2007. Tese (Doutorado em Educação) Universidade do Vale do Itajaí, Itajaí, 2015. 
LOUSADA, A.C.Z.; MARTINS, G.A. Egressos como fonte de informação a gestão dos cursos de ciências contábeis. Revista Contabilidade \&. Finanças, v.1, n.37, p. 73-84, 2005.

Disponível em: <http://www.scielo.br/scielo.php?script=sci_arttext\&pid=S151970772005000100006>. Acesso em: 14 out 2014.

MEIRA, M.D.D.; KURCGANT, P. Avaliação de curso de graduação segundo egressos. Revista da Escola de Enfermagem da USP, v. 43, n. 2, p. 481-485, 2009. Disponível em: <http://www.scielo.br/pdf/reeusp/v43n2/a31v43n2.pdf>. Acesso em: 15 out 2014.

MUÑOZ. F. I. A formação dos professores e o desenvolvimento do currículo. In. SACRISTÁN, J. G. (Org.). Saberes e incertezas sobre o currículo. Porto Alegre: Penso, 2013. p.494-507.

SACRISTÁN, J. G. O currículo na sociedade da informação e do conhecimento. In. p.153-172.

(Org.). Saberes e incertezas sobre o currículo. Porto Alegre: Penso, 2013.

O currículo em ação: as tarefas de ensinar e aprender - uma

análise do método.

Alegre: Penso, 2013. p.262-280.

. O que significa o currículo. In.

. (Org.) Saberes e incertezas

sobre o currículo. Porto Alegre: Penso, 2013. p.16-35.

SAVIANI, D. O trabalho como princípio educativo frente às novas tecnologias. In. FERRETIC,. J. et al. (Orgs.). Tecnologia, trabalho e educação. Petrópolis: Vozes, 1994. p.1-15.

SHIROMA, E. O.; COAN, M. Educação para o empreendedorismo: forjando um jovem de novo tipo? In. SILVA, M. M. da; QUARTIERO, E. M.; EVANGELISTA, O. (Orgs.). Jovens, trabalho e educação: a conexão subalterna de formação para o capital. Campinas: Mercado de Letras, 2012. (Série Educação Geral, Educação Superior e Formação Continuada do Educador). p.245-276.

ZABALZA, M.A. O ensino universitário: seu cenário e seus protagonistas. Porto Alegre: Artmed, 2004. 